\title{
Income Tax Evasion Responses to Tax Rate and Tax Enforcement Rate
}

\author{
Insook Lee \\ Peking University HSBC Business School, University Town, Nanshan District, Shenzhen, 518055, China
}

Copyright $(2018$ by authors, all rights reserved. Authors agree that this article remains permanently open access under the terms of the Creative Commons Attribution License 4.0 International License

\begin{abstract}
This paper resolves two lingering theoretical ambiguities on how income tax evasion is affected by income tax rates and by probability of detecting the tax evasion (tax enforcement rate). Improving upon the models of previous studies that showed the ambiguous effect of income tax rate and tax enforcement rate on tax evasion, the model of this paper allows taxpayers to decide both tax evasion and labor supply, responding to nonlinear income tax schedule and enforcement rate, while it also allows the government to decide both tax schedule and tax enforcement rate. With endogenous labor supply and tax evasion of taxpayers as well as endogenous decision of the government on tax rates and tax enforcement rate, the model of this paper more general than the models of previous studies. With this general model, we resolve the ambiguity as follows. First, we show that income tax evasion always responds positively to an increase in the income tax rate. Second, we also prove that income tax evasion is always negatively affected by an increase in the rate of tax enforcement, which invalidates the puzzling case that enhanced tax enforcement can increase income tax evasion.
\end{abstract}

Keywords Effect of Tax Rate on Tax Evasion, Effect of Tax Enforcement Rate on Tax Evasion, Nonlinear Income Taxation in Presence of Tax Evasion

\section{Introduction}

\subsection{Objective and Relevance of the Study}

Income tax evasion has long been a serious problem. For example, in the US, income tax revenue leakage was estimated at \$197 million in 2001 [1]; moreover, in Italy, tax evasion was estimated at $€ 285$ billion in 2012 (18\% of
GDP). ${ }^{1}$ The size of income tax evasion is much greater in developing countries [2]. Moreover, for governments to deal with income tax evasion problems, tax rate and tax audit to detect the evasion are one of the key policy instruments. Despite the importance of tax evasion issue, economic theory has not yet provided a clear answer to the fundamental questions of how income tax evasion is affected by income tax rate and by probability of detecting income tax evasion (tax enforcement rate). At most, previous studies have only shown that income tax evasion may respond positively or negatively to the tax rate and to the detecting probability. In particular, the latter means that improvement in the tax enforcement can increase income tax evasion, which is clearly puzzling. The present paper aims to resolve these two lingering theoretical ambiguities regarding income tax evasion responses to the income tax rates and to the probability of detecting the tax evasion (the enforcement rate).

\subsection{Review of the Related Literature}

To date, the attempts for theoretically clarifying the effect on income tax evasion of income tax rate and of tax enforcement rate have not been successful, ever since the very first paper that formulated income tax evasion behavior by Allingham and Sandmo[3]. The model of Allingham and Sandmo[3] is limited in that it allows neither individual taxpayers to determine their own labor supplies by assuming that their labor incomes are exogenously given nor income tax rates to vary by different levels of reported income. However, the limitation that individuals cannot choose their own labor supplies is problematic. Notably, for optimally responding to a reform in income tax rate or in tax enforcement rate, taxpayers should accurately reflect a concomitant change in the marginal value of their income tax evasion, which depends on the marginal value of providing

\footnotetext{
${ }^{1}$ Tax evasion in Italy: Big government meets big data (January 8th 2013) Economist. http://www.economist.com/node/21569195
} 
their labor to earn the income itself (part of which is to be evaded) because the concurrent change in the marginal value of labor supplies depends on the utility from the income after paying post-reform taxes if the tax evasion is not detected or after paying the penalty if the tax evasion is detected, with post-reform of detecting probability. In this regard, the subsequent studies of Pencavel[4], Baldry[5], and Horowitz and Horowitz[6] have improved upon the model of Allingham and Sandmo[3] by allowing individual taxpayers to jointly decide their labor supply and degree of tax evasion. In spite of this improvement, the latter three papers still failed to resolve the theoretical indeterminateness regarding income tax evasion responses to the tax rate and to the tax enforcement rate, respectively. That is, all of the three papers theoretically show that these responses can take both positive and negative signs, instead of taking one sign decisively even among the taxpayers who clearly evade income tax. This implies that we cannot rule out a puzzling case where an increase in tax enforcement rate can increase tax evasion.

One of the reasons for the failure of the above four studies is the assumption that income tax rates are exogenously given parameters. ${ }^{2}$ That is, their models do not allow the government to choose different income tax rates for different levels of reported labor earnings. This restriction can obscure government's evaluation of the marginal value of taxpayers' labor to earn their income and the marginal value of their income tax evasion. Sandmo[7] let the government derive an optimal linear income tax schedule in the presence of tax evasion. However, his model did not clearly separate labor supply decision from tax evasion decision by assuming that the proportion of tax evaders in the population is exogenously given. In addition, his model imposes a constant tax rate to different levels of incomes. On the other hand, Chander and Wilde [8] allow the government to choose tax rates differently for different levels of income. Nevertheless, their model does not allow individual taxpayers to choose their own labor supply by assuming that their labor incomes are exogenously given. Not surprisingly, Sandmo[7] and Chander and Wilde[8] also failed to clarify the ambiguities regarding the effect on income tax evasion of income tax rate and of probability of detecting the tax evasion.

In the optimal nonlinear income taxation literature where the government selects income tax rates varying by different levels of labor earnings that are chosen by individual taxpayers, tax evasion has been ignored by the unrealistic assumption of perfect enforcement of the tax code (e.g., $[9,10])$. In reality, perfect implementation of any income tax schedule is not guaranteed for free. Rather, the enforcement of tax rules is costly. Obviously, if the government could have implemented tax rules with no cost, the sizable tax

2 As Baldry[5] and Horowitz and Horowitz[6] assumed linear income taxation, they used one parameter to depict the tax rate. On the other hand, Pencavel[4] assumed nonlinear income taxation and used two parameters to describe the tax rate. evasions would have not existed. On the other hand, previous studies on optimal tax enforcement (e.g. $[11,12,13])$ assume that government maximizes net tax revenue, instead of social welfare which is the maximand in the optimal nonlinear income taxation literature. Once the enforcement of tax rules is imperfect and costly, the government should choose both tax rates and tax enforcement policies at the same time, for maximizing social welfare, as a benevolent social planner.

\subsection{Research Design and Contribution}

In line with the objective of this study to resolve the two lingering theoretical ambiguities, this study conducts theoretical analysis with a general model. In particular, the present paper improves on the previous studies by overcoming the aforementioned limitations as follows. First, we allow individual taxpayers to decide both labor supply and degree of tax evasion, responding to given nonlinear income tax schedule (different tax rates on different levels of reported earnings) and tax enforcement policy variables. Second, we also let the government choose nonlinear income tax schedule with the consideration of the taxpayers' tax evasion and labor supply responses. Third, we relax the unrealistic assumption of perfect tax enforcement by allowing the tax enforcement to be imperfect and costly. Thus, in its maximizing social welfare, the government chooses nonlinear income tax schedule as well as tax enforcement policy variables.

These improvements enable this paper to make the contribution of resolving the two lingering theoretical ambiguities regarding income tax evasion responses to income tax rates and to tax enforcement rates. First, the proof that a rise in income tax rate increases income tax evasion is provided. Second, this paper shows that effect of tax enforcement rate on income tax evasion is negative; refuting the puzzling case (from the theoretical ambiguities) that enhancing tax enforcement may increase tax evasion.

This paper is organized as follows. Section 2 presents a theoretical model where heterogeneous taxpayers choose tax evasion and labor supply to maximize their own utility and the government selects nonlinear income tax schedule and tax enforcement rate to maximize social welfare. Based on the theoretical formulation in Section 2, Section 3 investigates our main problem of how income tax evasion is affected by the tax rate and by the probability of detecting the tax evasion. Section 4 concludes the paper.

\section{The Model}

\subsection{Individual Taxpayers' Problem}

Consider a society populated by a continuum of individuals whose preference admits a utility representation that satisfies the Von Neumann-Morgenstern axioms. The 
preference is represented by a function $u(x, l)$, where $x$ $\in \mathfrak{R}_{+}$is a composite consumption good and $l \in(0,1)$ is the amount of time spent for working. We assume that $u(x, l)$ is strictly concave, continuously differentiable $\left(C^{1}\right.$ function), strictly increasing in $x$ and strictly decreasing in 1 . Importantly, individuals are differentiated by their innate earning abilities $n \in[\underline{n}, \bar{n}]$ with $n>0 . n$ is distributed according to a cumulative distribution function (hereafter, CDF) $H(n)$ with full support and a probability density function (hereafter, PDF) $h(n)$. When an individual of ability $n$ spends $l$ hours of working, his effective labor is $L \equiv n l$. An individual with higher $n$ earns higher income $(w L)$, given the wage rate $w$ and the amount of working $(l)$. Thus, the identifier variable $n$ indicates an individual's innate earning ability.

As the government assesses taxes based on voluntarily reported incomes and can detect and penalize tax evasion with probability $p \in(0,1)$, a rational taxpayer will consider understating his income to the tax authority. Denoting the ratio of reported income to true income as $r \in(0,1]$, an individual can choose his degree of tax evasion with choosing a value of $r$, given a tax schedule $T$ and tax enforcement policies. ${ }^{3}$ After the individual reports his income to the tax authority, the report is audited with the probability $p$. As the audit always can detect any income tax evasion, the probability to be penalized is $p$. If tax evasion is detected, then disposable income for consumption of an individual of ability $n$ is $x^{D}=w n l-T(w n l)-\theta\{T(w n l)$ $-T(r w n l)\}$ where $\theta$ is penalty rate. If tax evasion is not detected, he can consume as much as $x^{N D}=w n l-$ $T(w n l)$. In sum, the expected utility of the individual of ability $n$ is stated as.

$$
\begin{aligned}
& p u(w n l-T(w n l)-\theta\{T(w n l)-T(r w n l)\}, l)+ \\
& +(1-p) u(w n l-T(r w n l), l)
\end{aligned}
$$

For short, let this be denoted as $E[u(w n l-T(r w n l), l)]$. Then, given the income tax schedule $T$, the penalty rate $\theta$ and the enforcement rate $p$, the individual solves

$$
\max _{r, l} E[u(w n l-T(r w n l), l)]
$$

to obtain his indirect utility function $v_{n} \equiv E\left[u\left(w n l_{n}\right)-\right.$ $\left.\left.T\left(r_{n} w n l_{n}\right), l_{n}\right)\right]$.

To begin with characterizing optimal understatement of income $\left(r_{n}\right)$, the first-order condition (henceforth, FOC) for $r_{n}$ is

\footnotetext{
${ }^{3}$ Because the government knows that each individual taxpayer works (as $l>0$ ) and thus earns some positive amount of taxable income as $\forall n>0$, none of risk averse taxpayers would report zero income by choosing $r=0$ which surely reveals tax evasion without an audit.
}

$$
p \theta u_{1}^{D}=(1-p) u_{1}^{N D}
$$

where $u_{1}^{D}$ is the marginal utility of consumption if tax evasion is detected and penalized and $u_{1}^{N D}$ is the marginal utility of consumption if tax evasion is not detected. In other words, the optimal evasion level $e_{n}$, which is equal to $1-r_{n}$, is chosen to equalize the expected marginal utility of consumption that the taxpayer obtains when his tax evasion is detected (the left hand side: expected marginal loss of tax evasion) with the expected marginal utility of consumption that he obtains when his tax evasion is not detected (the right hand side: expected marginal gain of tax evasion). Essentially, tax evasion is an investment in a risky gamble with two possible outcomes (depending on whether tax evasion is detected or not). Thus, the decision regarding degree of tax evasion $\left(e_{n}\right)$ is about the degree to which a taxpayer exposes his labor earnings disposable for consumption to uncertainty (either $x^{N D}$ or $x^{D}$ ), which otherwise would certainly be $u\left(w n l_{n}\right)-T\left(w n l_{n}\right)$. Notice that the characterization of optimal tax evasion (3) presumes interior solution of $r_{n}$. As we focus our investigation to the relevant and realistic cases where tax evasions occur, we rule out the corner solution case of $r_{n}=1$. That is, assume $\left.\frac{\partial E[u(w n l-T(r w n l), l)]}{\partial r}\right|_{r=1}<0$ which is equivalent to $\frac{p \theta}{(1-p)}<1$. Noticeably, the set of parameters $\left\{p, \theta \mid p \in(0,1)\right.$ and $\left.\frac{p \theta}{(1-p)}<1\right\}$ is not empty and realistically plausible. ${ }^{4}$

Fundamentally, the income for investing in the tax evasion gamble is earned by taxpayer's labor. Hence, the uncertainty of income tax evasion on the final consumption carries over to the marginal value of working $\left(-u_{2}\right)$. That is, if tax code is enforced with penalizing the income tax evasion, $-u_{2}=u_{1}^{D} w n\left\{1-\left(1+\theta\left[1-r_{n}\right]\right) T^{\prime}\right\} ;$ otherwise, $-u_{2}=u_{1}^{D} w n\left[1-r_{n}\right] T^{\prime}$. Taking these together, the condition of optimal labor supply $l_{n}$ is stated as

$$
p u_{1}^{D} w n\left\{1-\left(1+\theta\left[1-r_{n}\right]\right) T^{\prime}\right\}+(1-p) u_{1}^{N D} w n\left(1-r_{n} T^{\prime}\right)=-u_{2} .
$$

That is, the optimal working hours $l_{n}$ are chosen to equalize the marginal disutility of working (the right hand side) with the expected marginal utility from disposable income for consumption (the left hand side: expected marginal gain of working). In turn, from the optimal

4 For instance, when the audit probability is $5 \%$, the value of $p /(1-p)$ is only 0.0526 allowing $\theta$ to take very high value greater than $10(1000 \%)$. In the US, $\theta$ is set as 0.2 as the IRS charges a penalty of $20 \%$ of unpaid tax liabilities for the case of a substantial understatement of income tax. 
working hours $l_{n}$ defined by (4), the effective labor supply of an ability- $n$ individual is derived as $L_{n} \equiv n l_{n}$ which determines his income $\left(w L_{n}\right)$ as well. Thus, in designing an income tax schedule $T$, the government can use (4) to know how much labor earnings are made by an individual of ability $n$ responding to the income tax schedule $T$ if the tax rates are precisely applied to the intended individuals.

In addition, there is a representative profit-maximizing firm that supplies the composite good under a perfect competition, using the variable input of labors that are supplied by individual taxpayers. The technology of the firm is characterized by a production function $F(L)$ which exhibits constant returns to scale and satisfies $F(0)=0$. Because only relative prices matter, without loss of generality, we normalize the price of the composite good to one. Thus, the firm solves $\max _{L} F(L)-w L$, where $w$ is the market wage rate. The FOC of the firm's optimization is $w=F^{\prime}$, which implies that the firm earns zero economic profit, based on Euler's homogeneous functions theorem. Hence, the aggregate output of the economy is stated as $F\left(\int_{n}^{\bar{n}} L_{n} h(n) d n\right)=\int_{n}^{\bar{n}} w L_{n} h(n) d n$, from which we obtain the aggregate resource constraint of the economy as $\int_{\underline{n}}^{\bar{n}}\left\{p x_{n}^{D}+(1-p) x_{n}^{N D}\right\} h(n) d n \leq \int_{\underline{n}}^{\bar{n}} w L_{n} h(n) d n$.

\subsection{Government's Problem}

The government determines income tax schedule $T$ as well as tax enforcement policies of $p$ and $\theta$. For tractable analysis, let income tax schedule $T$ be piece-wise continuously differentiable. In designing these tax policies, the government respects the utility of each individual and pursues to maximize a social welfare function $W\left(v_{\underline{n}} \cdots v_{n} \cdots\right.$

$\left.v_{\bar{n}}\right)$ (henceforth, SWF) which is a weighted sum of individuals' utilities. As the economy is populated by a continuum of individuals, the SWF is stated as $W=$ $\int_{\underline{n}}^{\bar{n}} \frac{d G}{d v_{n}} v_{n} h(n) d n$, where $\frac{d G}{d v_{n}}$ is the social marginal value on the utility of ability- $n$ individuals. As the government respects each individual's utility, $\infty>\frac{d G}{d v_{n}}>0$ for $\forall n$. Regarding distributional preference of the government, we let $\frac{d}{d v_{n}}\left(\frac{d G}{d v_{n}}\right) \leq 0$; that is, the government does not give greater weights to individuals who enjoy higher level of utility, implying that the SWF is weakly concave. ${ }^{5}$

5 As a result, imposing taxes is socially desirable. To see why, note that marginal utility from one unit of the consumption good is higher for individuals with lower values of utility. Thus, the government can increase
Most importantly, the government cannot directly observe and verify the innate earning ability of an individual at any cost, due to its nature as an inner characteristic, although the government can observe true income of the individual after auditing. The unobservability of earning ability follows the standard approach proposed by Mirrlees[9] which has still been widely used in optimal nonlinear taxation studies so far. However, unlike the standard approach, we do not assume that announcing an income tax schedule $T$ automatically guarantees its perfect execution. We admit that tax enforcement is costly and imperfect. ${ }^{6}$ Namely, $p$ refers to the overall rate of tax enforcement, as the government can surely verify the degree with which individual taxpayers evade their tax liabilities and penalize the tax evasion, with the auditing rate of $p$. Moreover, the cost for improving the tax enforcement rate $p$ is described by a cost function $\frac{1}{\delta} c(p)$, where $\delta \in(0, \infty)$ is a parameter reflecting efficiency of tax enforcement system; and, $c(p)$ is strictly convex and increasing in $p$ with $\frac{1}{\delta} c(p)>0$. This implies that the government decides the level of $p$ by directly choosing $\frac{1}{\delta} c(p)$ (the fiscal expenditure for the tax enforcement) since the cost function is invertible.

In addition to choosing $p$, the government decides penalty rate $\theta$ that it charges on unpaid (evaded) tax due when it detects tax evasion. ${ }^{7}$ Although legislating penalty rate of $\theta$ is an almost costless measure to curb tax evasion, the government cannot legislate $\theta=\infty$ to be in harmony with other penalties on crimes that seriously threaten the society. Let $\bar{\theta}>0$ denote the maximum penalty rate on tax evasion under a given legal hierarchy of the society. After all, the government will select $\theta=\bar{\theta}$ to deter revenue leakage as much as possible.

All in all, the problem that the government seeks to solve can be written as ${ }^{8}$

social welfare through a redistribution via income taxation, unless the government puts more weights individuals with higher levels of utility.

6 In practice, revenue mobilization through tax enforcement involves various phases, each of which is costly. In the first place, an established taxation system and a professional workforce that transparently administers the tax system are not given for free, while they are important prerequisite infrastructures for tax collection and tax enforcement. In addition, maintaining and operating the tax system also incurs enormous administrative costs. For example of US, its tax collection agency Internal Revenue Service (IRS) spends \$10 billion for maintaining individuals' tax return files alone, which must be a very small fraction of administrative cost [14]. In light of this, the total cost for tax enforcement would be sizable. Without such costs for establishing a transparent tax system and for having the system operate well, tax audits alone may not successfully detect and verify fraudulent tax evasion.

7 This is closer to reality than charging a constant amount of fine; for instance of the US, the IRS charges a penalty of $20 \%$ of unpaid tax liabilities for the case of a substantial understatement of income tax.

8 Notice that the government's own budget constraint is not added as it is redundant, according to the Walras' law. 


$$
\begin{gathered}
\max _{T(\cdot) \& p} \int_{\underline{n}}^{\bar{n}} \frac{d G}{d v_{n}} v_{n} h(n) d n \text { subject to } \int_{\underline{n}}^{\bar{n}}\left\{p x_{n}^{D}+(1-p) x_{n}^{N D}\right\} \\
h(n) d n \leq \int_{\underline{n}}^{\bar{n}} w n l_{n} h(n) d n
\end{gathered}
$$

Moreover, the time line is as follows: (i) income tax schedule $T$ as well as $p$ and $\bar{\theta}$ are announced by the government; and, (ii) individual taxpayers make decisions regarding their working hours $\left(l_{n}\right)$ and degree of tax evasion $\left(e_{n}=1-r_{n}\right)$.

In its search for an optimal income tax schedule $T(\cdot)$ that is, in fact, a function, the government first needs to identify each element in the domain of $T$ with the source of income difference which is individuals' earning ability $n$. Only after having identified each $n$ in the domain of $T$, the government can accurately assess the level of utility of taxpayers from their decisions $\left(l_{n}\right.$ and $\left.e_{n}\right)$, based on (3) and (4), for maximizing the SWF. This fundamental task of assessment is not feasible unless the tax rate for each $n$ takes effect precisely on the targeted individuals of ability $n$; however, it is not automatically fulfilled because the government cannot observe $n$ (the innate earning ability of an individual). Rather, the link between tax rates and taxpayers' earning abilities is not secured simply by an income tax schedule alone, because the government is redistributive. As higher tax liabilities are imposed for individuals of higher earnings abilities, an individual of ability $n$ can be better off with pretending to be of lower ability $n^{\prime}$ (where $n^{\prime}<n$ ) by reducing his working hours so that his effective labor supply is $L_{n^{\prime}}$ (instead of $L_{n}$ that is greater than $L_{n^{\prime}}$ ). By doing so, the ability $n$ individual can enjoy more consumption with less disutility of working because $\exists l_{n^{\prime \prime}}$ such that $L_{n^{\prime}}=n^{\prime} l_{n^{\prime}}=n l_{n^{\prime \prime}}$ and $l_{n^{\prime}}>l_{n^{\prime \prime}}$. Although an individual cannot mimic another individual by manipulating the level of income tax evasion $\left(e_{n}\right)$ as the government is able to fully verify the tax evasion, the individual still can pretend to be another individual since the government cannot verify innate earning ability. Thus, for addressing this problem, the government should provide incentives for individuals to voluntarily reveal their own earning abilities.

The next subsection will elaborate on the conditions necessary for the government to build the missing link between tax rates and taxpayers' earning abilities, which may simplify the originally complex task of finding the optimal tax function into point-wise maximizations.

\subsection{Simplification of Government's Optimization}

As mentioned above, because the government can observe true income after auditing tax evasion, the only way an individual disguises himself as another individual of lower ability is to reduce his working hours, not to garble the degree of understating his income. To neatly express the disguise, denote the payoff to an individual of ability $n$ when he pretends to be of ability $n^{\prime}$ as $V\left(n^{\prime} \mid n\right) \equiv$ $E\left[u\left(w L_{n^{\prime}}-T\left(r_{n}, w L_{n^{\prime}}\right), \frac{L_{n^{\prime}}}{n}\right)\right]$. In this line, the payoff to an individual of ability $n$ when he does not pretend to be another individual (i.e., voluntarily reveals his own earning ability) is $V(n \mid n)=v_{n}=E\left[u\left(w L_{n}-T\left(r_{n} w L_{n}\right), \frac{L_{n}}{n}\right)\right]$. Using this notation, the condition that gives ability- $n$ individual taxpayers the incentive not to pretend those of other ability $n^{\prime}$ can be stated as $V(n \mid n) \geq V\left(n^{\prime} \mid n\right)$, which is referred to as incentive compatibility constraint (hereafter, IC constraint). In addition, to induce all the individual taxpayers to remain as taxpayers, $V(n \mid n)$ must not be less than $V(0 \mid 0)=u(-T(0), 0)$ (the payoff to non-taxpayers), which is referred to as participation constraint or individual -rationality constraint (henceforth, IR constraint). In sum, the conditions for regaining the missing link between the tax rates and the earning abilities of targeted taxpayers' are concisely stated as follows: For $\forall n \in[\underline{n}, \bar{n}]$, (IC) $V(n \mid n)$ $\geq V\left(n^{\prime} \mid n\right)$ for $\forall n^{\prime} \neq n$ and (IR) $V(n \mid n) \geq u(-T(0), 0)$. Once these two sets of requirements are met, the government can now locate itself in the domain of an income tax function $T$ as if it knows the unobservable earning abilities of individual taxpayers. Then, an optimal income tax schedule that maximizes the SWF can be translated into maximizing the SWF with each $n$ given to find the optimal tax rate for the ability- $n$ taxpayers. In other words, finding the optimal income tax function $T$ is simplified into point-wise maximizations.

Because the IC and IR constraints still involve infinite numbers of inequalities for each given $n$, we need to reduce these constraints into more tractable forms.

Lemma 1. For any given $n \in[\underline{n}, \bar{n}]$, the IC constraint is met if and only if (i) $L_{n}$ is non-decreasing in $n$; and, (ii) $V_{1}(n \mid n)=0$ where $V_{1}(n \mid n)$ is a partial derivative with respect to the first argument of $V(n \mid n)$.

\section{Proof. See Appendix.}

Lemma 2. For any given $n \in[\underline{n}, \bar{n}]$, if the IC constraint is met, then the IR constraint is met.

\section{Proof. See Appendix.}

Now, we transform (i) and (ii) in Lemma 1 into the same terms of (3) and (4) which the government eventually needs to use for maximizing the SWF.

Lemma 3. For any given $n \in[\underline{n}, \bar{n}]$, the IC constraint and IR constraint are met if and only if (i) $v_{n}=v_{\underline{n}}+\int_{\underline{n}}^{\bar{n}}-\frac{l_{t}}{t}$ $u_{2} d t$ and (ii) $\int_{\underline{n}}^{\bar{n}}-\frac{l_{t}}{t} u_{2}\left[p \frac{1}{u_{1}^{D}}+(1-p) \frac{1}{u_{1}^{N D}}\right] d t \geq 0$. 


\section{Proof. See Appendix.}

In (i) in Lemma 3, which is $v_{n}$ the payoff to an individual of ability $n$, the first term $v_{n}$ is the reservation utility to retain an ability- $n$ individual as a taxpayer, because it is the payoff to an individual of the lowest earning ability $(\underline{n})$ that is greater than $u(-T(0), 0)$ as IR constraint is met. The second term is compensation to the ability $n$ individual for not-pretending to be of lower abilities by decreasing his working hours, which is referred to as the "informational rent." As the second term contains its own specific notion, let us introduce the notation for this rent as $\pi_{t} \equiv-\frac{l_{t}}{t} u_{2}$.

As the informational rent is neither tax revenue nor produced output, the resources needed for the rent impose an additional constraint on the government's problem as (ii) in Lemma 3. After converting the information rent in the unit consistent with other government's resource constraints (in the unit of composition goods), the government aggregates the resources necessary for the informational rents to all the taxpayers with their population weights $h(n)$ to obtain $\int_{\underline{n}}^{\bar{n}} \int_{\underline{n}}^{n} \pi_{t}\left[p \frac{1}{u_{1}^{D}}+(1-p) \frac{1}{u_{1}^{N D}}\right] d t h(n) d n \geq 0$.

In sum, by incorporating the conditions derived in Lemma 1, 2, and 3 for building the missing link between the tax rates and the earning abilities of targeted taxpayers' into (5), we can rewrite the government's problem as follows: For $\forall n \in[\underline{n}, \bar{n}]$ given,

$$
\begin{aligned}
& \max _{\left\{l_{n}, E\left[x_{n}\right]\right\}} \int_{\underline{\underline{n}}}^{\bar{n}} \frac{d G}{d v_{n}}\left(v_{\underline{\underline{n}}}+\int_{\underline{\underline{n}}}^{n} \pi_{t} d t\right) h(n) d n \quad \text { subject } \text { to (i) } \int_{\underline{\underline{n}}}^{\bar{n}}\left\{p x_{n}^{D}+\right. \\
& \left.(1-p) x_{n}^{N D}\right\} h(n) d n \leq \int_{\underline{\underline{n}}}^{\bar{n}} n w l_{n} h(n) d n \quad \text { and } \quad \text { (ii) } \int_{\underline{\underline{n}}}^{\bar{n}} \int_{\underline{\underline{n}}}^{n} \pi_{t}
\end{aligned}
$$$$
\left[p \frac{1}{u_{1}^{D}}+(1-p) \frac{1}{u_{1}^{N D}}\right] d t h(n) d n \geq 0
$$

Equivalently, this is stated in its Lagrangian form $\mathfrak{I}$ as follows: for $\forall n \in[\underline{n}, \bar{n}]$ given,

$$
\begin{aligned}
& \left\{\int_{\underline{n}}^{\bar{n}} \int_{n}^{\bar{n}}\left\{\frac{d^{2} G}{d v_{t}^{2}}\left[\frac{v_{\underline{n}}}{n-\underline{n}}+\pi_{t}\right]-\lambda \pi_{t}\left[p \frac{1}{u_{1}^{D}}+(1-p) \frac{1}{u_{1}^{N D}}\right]\right\} h(t) d t d n\right. \\
& +\int_{\underline{n}}^{\bar{n}} \lambda\left\{w n l_{n}-\left[p x_{n}^{D}+(1-p) x_{n}^{N D}\right]\right\} h(n) d n
\end{aligned}
$$

where $\lambda$ is the marginal social value on resources for public fund. ${ }^{10}$

Then, we can obtain an optimal tax rate for earning ability $n$ individuals by maximizing the above Lagrangian form $\mathfrak{I}$ of (7) with any given $n \in[\underline{n}, \bar{n}]$ and $p$ (point-wise maximization). Furthermore, with any given $p$, once both before-tax income and expected after-tax income disposable for consumption of individuals of ability $n$ are determined, the income tax rate for individuals of ability $n$ is automatically determined. In this light, by finding $l_{n}$ and $E\left[x_{n}\right]$ that maximize the SWF with a simple calculus, the government obtains the optimal income tax rate for ability $n$ individuals. Then, by applying this approach to individuals of each ability for $\forall n \in[\underline{n}, \bar{n}]$, the government eventually obtains entire part of the optimal income tax schedule $T$.

\subsection{Optimal Income Tax Schedule and Optimal Rate of Tax Enforcement}

In this subsection, we characterize the formula for the optimal tax function, based on (7) and proceed to characterize optimal $p$ (rate of tax enforcement). With the Lagrangian form $\mathfrak{I}$ of (7) the government obtains the optimal tax rate for each $n \in[\underline{n}, \bar{n}]$ by finding $l_{n}$ and $E\left[x_{n}\right]$ that maximize the SWF. As the SWF is weakly concave (i.e., $\frac{d^{2} G}{d v_{n}^{2}} \leq 0$ ), the FOCs of (7) with respect to $l_{n}$

10 To be consistent, since the informational rent is forgone resource that could have been used for public fund, the Lagrange multiplier of $\int_{\underline{n}}^{n} \pi_{t}\left[p \frac{1}{u_{1}^{D}}+(1-p) \frac{1}{u_{1}^{N D}}\right] d t$ is $-\lambda$. At the same time, the double integrals of $\int_{\underline{n}}^{\bar{n}}\left\{\frac{d G}{d v_{n}}\left[v_{\underline{n}}+\int_{\underline{n}}^{n} \pi_{t} d t\right]\right\} h(n) d n$ and the constraint (ii) in (6) are simplified as follows.

$\int_{\underline{\underline{n}}}^{\bar{n}}\left\{\frac{d G}{d v_{n}}\left[v_{\underline{n}}+\int_{\underline{\underline{n}}}^{n} \pi_{t} d t\right]-\lambda \int_{\underline{\underline{n}}}^{n} \pi_{t}\left[p \frac{1}{u_{1}^{D}}+(1-p) \frac{1}{u_{1}^{N D}}\right] d t\right\} h(n) d n$ $=\int_{\underline{n}}^{\bar{n}} \int_{\underline{\underline{n}}}^{n}\left\{\frac{d^{2} G}{d v_{n}^{2}}\left(\frac{v_{\underline{n}}}{n-\underline{n}}+\pi_{t}\right)-\lambda \pi_{t}\left[p \frac{1}{u_{1}^{D}}+(1-p) \frac{1}{u_{1}^{N D}}\right]\right\} d t h(n) d n$ $=\int_{\underline{n}}^{\bar{n}} \int_{n}^{\bar{n}}\left\{\frac{d^{2} G}{d v_{t}^{2}}\left(\frac{v_{\underline{n}}}{n-\underline{n}}+\pi_{t}\right)-\lambda \pi_{t}\left[p \frac{1}{u_{1}^{D}}+(1-p) \frac{1}{u_{1}^{N D}}\right]\right\} h(t) d t d n$
9 The government cannot distinguish an individual of ability $n$ who pretends to be of slightly lower ability $n-\varepsilon$ (where $\varepsilon>0$ ) from an individual who truly is of ability $n-\varepsilon$. The payoff to the former is $V(n-\varepsilon \mid n)$, while the payoff to the latter is $V(n-\varepsilon \mid n-\varepsilon)$. Hence, the surplus that the individual of ability $n$ can exploit as a result of the government's inability to see innate earning ability is $V(n-\varepsilon \mid n)-$ $V(n-\varepsilon \mid n-\varepsilon)$. Unless the individual of ability $n$ is compensated by this amount, he would rather mislead the government into believing him to be an ability $n-\varepsilon$ individual. By the same reasoning, the compensation required to deter the ability $n$ individual from pretending to be an individual of the closest lower ability is $\lim _{\varepsilon \rightarrow 0}\{V(n-\varepsilon \mid n)-V(n-\varepsilon \mid n-\varepsilon)\} / \varepsilon=$ $V_{2}(n \mid n)$. Aggregating the surplus of pretending to be of all the other lower abilities results in $\int_{n}^{n} V_{2}(t \mid t) d t$. This is the second term of the payoff $v_{n}$, because $V_{2}(t \mid t)=-\frac{l_{t}}{t} u_{2}$. 
and $E\left[x_{n}\right]$ are sufficient. Combining the two FOCs $\left(\frac{d \mathfrak{I}}{d l_{n}}=0\right.$ and $\left.\frac{d \mathfrak{I}}{d E\left[x_{n}\right]}=0\right)^{11}$ yields the optimality condition of income tax rate as follows: For each $n \in[\underline{n}, \bar{n}]$,

$$
\begin{aligned}
& \frac{d \pi_{n}}{d l_{n}} \int_{n}^{\bar{n}}\left[\lambda\left\{p \frac{1}{u_{1}^{D}}+(1-p) \frac{1}{u_{1}^{N D}}\right\}-\frac{d^{2} G}{d v_{t}^{2}}\right] h(t) d t \\
& =w n \lambda\left[p\left\{1+\bar{\theta}\left(1-r_{n}\right)\right\}+(1-p) r_{n}\right] T^{\prime} h(n)
\end{aligned}
$$

The left-hand side of (8) is marginal social value on the net information rent for preventing taxpayers from pretending to be of lower earning ability, as $\frac{d^{2} G}{d v_{n}^{2}}$ is the marginal social value of an increase in the utility of ability $t$ individuals from receiving the information rent. On the other hand, the right-hand side of (8) is social value of the marginal increase in tax revenue. Furthermore, when the fine for tax evasion paid to the government is perceived as part of the tax payment, $\left[p\left\{1+\bar{\theta}\left(1-r_{n}\right)\right\}+(1-p) r_{n}\right] T^{\prime}$ is regarded as an effective ex-ante marginal income tax rate. In fact, under the assumption of perfect enforcement of income tax schedule $(p=1)$ which implies that $r_{n}=1$ for $\forall n,(8)$ is equal to the optimal income tax rate formula elaborated by Mirrlees[9]. The sign of the effective expected marginal tax rate is strictly positive except for singleton top earners (zero) as follows.

Lemma 4. If $T$ is an optimal income tax schedule, then for $\forall n \in[\underline{n}, \bar{n}], \quad\left[p\left\{1+\bar{\theta}\left(1-r_{n}\right)\right\}+(1-p) r_{n}\right] T^{\prime}>0$; and, for $n=\bar{n}, T^{\prime}=0$.

\section{Proof. See Appendix.}

Having characterized the optimal income tax schedule $T$ by (8), let us move on to defining the optimal rate of tax enforcement $p$ that maximizes the SWF. To this end, since $p$ governs tax revenue collection, we replace the market clearing condition in the government's problem (5) with its budget condition as follows.

$$
\max _{p} \int_{\underline{n}}^{\bar{n}} \frac{d G}{d v_{n}} v_{n} h(n) d n \text { subject to } \int_{\underline{n}}^{\bar{n}}\left[p \left\{T\left(w n l_{n}\right)+\bar{\theta}[T(w n\right.\right.
$$

$$
\begin{aligned}
& 11 \quad \frac{d \mathfrak{I}}{d l_{n}}=\frac{d \pi_{n}}{d l_{n}} \int_{n}^{\bar{n}}\left[\frac{d^{2} G}{d v_{t}^{2}}-\lambda\left\{p \frac{1}{u_{1}^{D}}+(1-p) \frac{1}{u_{1}^{N D}}\right\}\right] \\
& \left.h(t) d t+\lambda w n-\lambda \frac{d\left[p x_{n}^{D}+(1-p) x_{n}^{N D}\right]}{d l_{n}}\right] h(n)=0 \text { and } \frac{d \mathfrak{I}}{d E\left[x_{n}\right]} \\
& =\frac{d l_{n}}{d E\left[x_{n}\right]} \frac{d \pi_{n}}{d l_{n}} \int_{n}^{\bar{n}}\left[\frac{d^{2} G}{d v_{t}^{2}}-\lambda\left\{p \frac{1}{u_{1}^{D}}+(1-p) \frac{1}{\left.u_{1}^{N D}\right\}}\right\} h(t) d t+\lambda w n \frac{d l_{n}}{d E\left[x_{n}\right]}-\lambda\right] h(n)=0 \\
& \text { Moreover, } \quad \frac{d\left[p x_{n}^{D}+(1-p) x_{n}^{N D}\right]}{d l_{n}}=p \frac{d x_{n}^{D}}{d l_{n}}+(1-p) \frac{d x_{n}^{N D}}{d l_{n}}=p w n\left(1-T^{\prime}-\bar{\theta} T^{\prime}+\bar{\theta}_{r_{n}} T^{\prime}\right) \\
& +(1-p) w n\left[1-r_{n} T^{\prime}\right] .
\end{aligned}
$$

$$
\left.\left.\left.\left.l_{n}\right)-T\left(r_{n} w n l_{n}\right)\right]\right\}+(1-p) T\left(r_{n} w n l_{n}\right)\right] h(n) d n \geq R+\frac{1}{\delta} c(p)
$$

where $\mathrm{R}$ is a given required public expenditure. From the FOC of the Lagrangian expression of (9) with respect to $p$, we define optimal rate of tax enforcement as follows ${ }^{12}$

$\int_{\underline{n}}^{\bar{n}} \frac{d G}{d v_{n}}\left(u_{n}^{N D}-u_{n}^{D}\right) h(n) d n=\lambda \int_{\underline{n}}^{\bar{n}}(1+\bar{\theta})\left[T\left(w n l_{n}\right)-T\left(r_{n} w n l_{n}\right)\right]$

$h(n) d n-\frac{1}{\delta} c^{\prime}(p)$

where $u_{n}^{D}=u\left(w n l_{n}-T\left(w n l_{n}\right)-\bar{\theta}\left\{T\left(w n l_{n}\right)-T\left(r_{n} w n l_{n}\right)\right\}, l_{n}\right)$ (utility if tax evasion is detected and penalized) and $u_{n}^{N D}=u\left(w n l_{n}-T\left(r_{n} w n l_{n}\right), l_{n}\right)$ (utility if tax evasion is not detected). The right-hand side of (10) represents the marginal net social benefit ${ }^{13}$ from increasing $p$ while the left-hand side represents the marginal social loss from a decrease in the utility of risk-averse taxpayers due to the small increase in $p$ as $-\frac{d v_{n}}{d p}=u_{n}^{N D}-u_{n}^{D}$.

\section{Tax Evasion Responses to Income Tax Rate and to Tax Enforcement Rate}

Thus far, we have characterized optimal nonlinear income tax schedule and optimal enforcement rate that the government chooses with explicitly incorporating taxpayers' responses of both labor supply and tax evasion. This paves the way for us to achieve the aim of the present study: to resolve the theoretical ambiguities regarding income tax evasion responses to the tax rates and to the tax enforcement rates.

As mentioned at the outset, previous studies that discussed how income tax evasion is affected by income tax rate and by tax enforcement rate (e.g., [3-7]) only showed that the effects on tax evasion of tax rate and of tax enforcement rate are ambiguous. We are revisiting the pending questions on tax evasion responses to the two key tax policy variables. First, we address the issue of how

12 Notice that this result improves upon the previous studies on optimal tax enforcement [11-13]. First, the current analysis characterizes $p$ that maximizes social welfare whereas they found $p$ that maximizes net tax revenue only. More importantly, the present study derives both optimal nonlinear income tax schedule and optimal tax enforcement at the same time while previous studies separated these by assuming income tax rates exogenously given.

13 The first term $\int_{\underline{n}}^{\bar{n}}(1+\bar{\theta})\left[T\left(w n l_{n}\right)-T\left(r_{n} w n l_{n}\right)\right] h(n) d n$ represents the increase in expected tax revenue resulting from a small increase in $p$. We then subtract the second term $\frac{1}{\delta} c^{\prime}(p)$ that is an increment in enforcement costs needed for the increment in $p$. Lastly, this net resource for public funds (gain) is appraised at $\lambda$ per unit. 
income tax evasion responds to an increase in the income tax rate.

Theorem 1. For $\forall n \in[\underline{n}, \bar{n}], \frac{d e_{n}}{d T^{\prime}}>0$. That is, income tax evasion is positively affected by an increase in the marginal income tax rate.

\section{Proof. See Appendix.}

The intuition underlying Theorem 1 can be effectively demonstrated under the view that the income for investing in tax evasion gamble is purchased with taxpayer's labor. That is, an increment in the tax rate lowers the value of working to taxpayers $\left(-u_{2}\right)$, according to (4). As a result, the price for earning the same amount of labor income invested in the tax evasion gamble goes down, which entails more investment in the gamble of tax evasion. In other words, an increase in the tax rates causes a given amount of labor earnings to be less worthy as the same amount of labor earnings yield less ex-ante consumption, due to the ensuing increase in tax liabilities. Responding to this, taxpayers under-report a greater portion of their income to maintain their expected consumption, following (3), because an increase in $e_{n}$ (a decrease in $r_{n}$ ) entails an increase in expected consumption unless $T^{\prime}=0$.

Importantly, notice that Theorem 1 resolves the theoretical ambiguity regarding the income tax evasion responses to income tax rates. As a matter of fact, on the empirical front of this problem, a number of studies have already found a positive correlation between the tax rate and income tax evasion, using various data (e.g., [15-18]). Contrast to the prior literature, the differentiated features that enable the present study to clarify the theoretical ambiguity on tax evasion response to tax rate are the following two. First, responding to a change in the tax rate, our model allows individual taxpayers to accurately re-evaluate the marginal value of tax evasion by reflecting a concomitant change in the marginal value of labor supply, when the taxpayers adjust their tax evasion level. Second, our model also allows the government to choose different tax rates for different earning abilities lest the re-evaluation of the marginal value of taxpayers' labor earnings, part of which is to be evaded following (3), should be distorted. ${ }^{14}$

Let us now examine the effect on tax evasion behavior of an increase in the probability with which tax evasion is detected and penalized. As noted above, previous studies (e.g., [4-7]) have shown that an increase in $p$ can decrease or increase tax evasion. The latter is a particularly perplexing result, as it means that enhancing tax enforcement promotes tax evasion.

14 For instance, the linear taxation models (e.g. [6,7]) assume that $T^{\prime}$ can take the same value regardless of different levels of incomes. Moreover, it would not be rational that the government levies a constant tax rate regardless of different levels of incomes, as reducing income inequality is socially desirable.
Theorem 2. For $\forall n \in[\underline{n}, \bar{n}], \frac{d e_{n}}{d p}<0$. That is, income tax evasion is negatively affected by an increase in the tax enforcement rate.

.Proof. See Appendix.

The rationale for Theorem 2 is simple. Based on (3), as the likelihood of an undesired outcome from investing labor earnings in the tax evasion gamble (i.e., the likelihood of being penalized for the tax evasion) increases, the expected return from the tax evasion gamble decreases, making tax evasion less attractive. That is, responding to an increase in the tax enforcement rate, taxpayers reduce tax evasions by decreasing $e_{n}$ (i.e., increasing $r_{n}$ ) to maintain their expected after-tax consumptions. Most importantly, this means that enhanced tax enforcement will clearly decrease overall tax revenue leakage. Put another way, with Theorem 2, we now can invalidate the perplexing case where the government's improvement of tax enforcement causes tax evasion to increase.

Distinct from the previous studies [3-7], the present analysis clearly shows that the effect of an increase in tax enforcement rate on income tax evasion is negative. The factor that enables us to deliver this result is that our model allows individual taxpayers to accurately re-evaluate the price of the income tax evasion gamble when they adjust their tax evasion, according to both (3) and (4), in response to a change in the tax enforcement rate. Unlike the previous studies, our model lets the marginal utilities from taxpayers' after-tax consumptions depend on both their labor supply decisions and varying tax rates (nonlinear taxation).

\section{Concluding Remarks}

In sum, this paper presents clarification of the two theoretical ambiguities regarding income tax evasion responses to the tax rate and to the tax enforcement rate, which have been left unresolved for decades. To overcome the limitations of the previous studies that have failed to resolve the two theoretical ambiguities, our model allows individual taxpayers to choose both tax evasion and labor supply, while our model lets the government derive tax rates varying by different earning abilities and select the rate of tax enforcement (probability to detect income tax evasion) when improving the tax enforcement rate is costly. With such improvements, we show that an increase in income tax rate leads to an increase in the income tax evasion. Moreover, we prove that enhancing tax enforcement always decreases tax evasion, invalidating the puzzling case that the government's improvement of tax enforcement can promote tax evasion. Based on these theoretical findings, this can provide the following policy suggestion that enhancing tax enforcement will reduce leakage of tax revenue whereas raising income tax rate might not yield an increase in tax revenue as much as the 
increase in the tax rate.

\section{Appendix}

\section{Proof of Lemma 1.}

[step 1] $(\Rightarrow)$ Suppose that the IC constraint is met for an arbitrarily given $n \in[\underline{n}, \bar{n}]$; namely, $V(n \mid n) \geq V\left(n^{\prime} \mid n\right)$ for $\forall n \in[\underline{n}, \bar{n}]$. This means that $n=\arg \max V(t \mid n)$. First of all, this immediately implies that $V_{1}(n \mid n)=0$ as it is the necessary condition for $n=\arg \max V(t \mid n)$.

Next, by way of contradiction, suppose that $L_{n}=L(n)$ is decreasing in $n$; that is, $L^{\prime}=\frac{d L_{n}}{d n}<0$. Pick any arbitrary $n^{\prime}$ such that $n>n^{\prime}>\underline{n}$. Since the IC constraint is met, $V(n \mid n) \geq V\left(n^{\prime} \mid n\right) \quad$ which implies that $V(n \mid n)-V\left(n^{\prime}\right.$ $\mid n)=\int_{n}^{n}, V_{1}(t \mid n) d t \geq 0$. Moreover, $\int_{n}^{n}, V_{1}(t \mid n) d t=\int_{n}^{n}, V_{1}(t \mid n)-$ $V_{1}(t \mid t) d t$ because $V_{1}(t \mid t)=V_{1}(n \mid n)=0$. Since $V_{1}(t \mid n)$ $=\left[p u_{1}^{D} w\left\{1-\left(1+\bar{\theta}-r_{t} \bar{\theta}\right) T^{\prime}\right\}+(1-p) u_{1}^{N D} w\left(1-r_{t} T^{\prime}\right)\right] L^{\prime}+u_{2}$ $\frac{1}{n} L^{\prime}$ and $V_{1}(t \mid t)=\left[p u_{1}^{D} w\left\{1-\left(1+\bar{\theta}-r_{t} \bar{\theta}\right) T^{\prime}\right\}+(1-p) u_{1}^{N D}\right.$ $\left.w\left(1-r_{t} T^{\prime}\right)\right] L^{\prime}+u_{2} \frac{1}{t} L^{\prime}, \quad V_{1}(t \mid n)-V_{1}(t \mid t)=u_{2} \frac{1}{n} L^{\prime}-u_{2} \frac{1}{t} L^{\prime}=$ $u_{2} L^{\prime}\left[\frac{1}{n}-\frac{1}{t}\right]$. As a result, $\int_{n}^{n}{ }_{n} V_{1}(t \mid n) d t=\int_{n}^{n}{ }^{n} u_{2} L^{\prime}\left[\frac{1}{n}-\frac{1}{t}\right] d t<0$ because $L^{\prime}<0, u_{2}<0$, and $\frac{1}{n}-\frac{1}{t}<0$ for $\forall t \in\left(n^{\prime}, n\right)$. A contradiction to the IC constraint that implies that $\int_{n}^{n}, V_{1}(t \mid n) d t \geq 0$. This proves that $L^{\prime} \geq 0$.

[step 2] ( $\Leftarrow)$ ) Conversely, assume that (i) $L_{n}$ is non-decreasing in $n$ (i.e., $L^{\prime}=\frac{d L_{n}}{d n} \geq 0$ ) and (ii) $V_{1}(n \mid n)$ $=0$ for any given $n \in[\underline{n}, \bar{n}]$, this time. Now suppose that the IC constraint is not satisfied. Then, there exists some $n^{\prime} \in[\underline{n}, \bar{n}]$ such that $V(n \mid n)<V\left(n^{\prime} \mid n\right)$. Therefore, $n \neq$ $\arg \max V(t \mid n)$ which implies that $V_{1}(n \mid n)=0$ cannot be zero for some $n \in[\underline{n}, \bar{n}]:$ A contradiction to the assumption (ii). Therefore, this proves that the IC constraint is met.

\section{Proof of Lemma 2.}

By a way of contradiction, given that the IC constraint is met for an arbitrarily given $n \in[n, \bar{n}]$, suppose that the IR constraint is not met. Then, $V(n \mid n)<u(-T(0), 0)$. Moreover, when a taxpayer of ability $n$ pretends to be a non-taxpayer, his payoff $u(-T(0), 0)$ can be restated as
$V(0 \mid n)$. Thus, $V(n \mid n)<V(0 \mid n)$. Since $n \neq 0$ with $\underline{n}>0$, this contradicts to the IC constraint that $V(n \mid n) \geq$ $V\left(n^{\prime} \mid n\right)$.

\section{Proof of Lemma 3.}

[step 0] As a stepping stone to prove the above statement, we first need to show that for an income tax schedule $T, v_{n}$ is increasing in $n$. To show this, pick any $n$ and $n^{\prime}$ such that $n>n^{\prime}$. Because $u_{2}<0, E\left[u\left(w n^{\prime} l_{n},-T\left(r_{n}, w n^{\prime} l_{n}\right), l_{n}{ }_{n}\right)\right.$ ]$<E\left[u\left(w n \frac{n^{\prime}}{n} l_{n^{\prime}}-T\left(r_{n}, w n \frac{n^{\prime}}{n} l_{n}\right), \frac{n^{\prime}}{n} l_{n}{ }^{\prime}\right)\right] \leq E\left[u\left(w n l_{n}-T\left(r_{n}\right.\right.\right.$ $\left.\left.\left.w n l_{n}\right), l_{n}\right)\right]$. The first term $v_{n},=E\left[u\left(w n^{\prime} l_{n^{\prime}}-T\left(r_{n}, w n^{\prime} l_{n^{\prime}}\right)\right.\right.$ ,$\left.\left.l_{n}^{\prime}\right)\right]$ is the maximized utility of an ability $n^{\prime}$ individual. The second term $E\left[u\left(w n \frac{n^{\prime}}{n} l_{n^{\prime}}-T\left(r_{n}, w n \frac{n^{\prime}}{n} l_{n}{ }^{\prime}\right), \frac{n^{\prime}}{n} l_{n^{\prime}}\right)\right]$ is a value of utility of an ability- $n$ individual when he chooses his working hours as much as $\frac{n^{\prime}}{n} l_{n}$, and his report ratio as $r_{n}$. Clearly, $E\left[u\left(w n \frac{n^{\prime}}{n} l_{n^{\prime}}-T\left(r_{n}, w n \frac{n^{\prime}}{n} l_{n}\right), \frac{n^{\prime}}{n} l_{n^{\prime}}\right)\right] \quad$ is always smaller or equal to the maximized utility of the ability $n$ individual $v_{n}=E\left[u\left(w n l_{n}-T\left(r_{n} w n l_{n}\right)\right]\right.$. Taken together, this results in $v_{n}>v_{n}$. Therefore, $v_{n}$ is increasing in $n$ as $n>n^{\prime} \Rightarrow v_{n}>v_{n^{\prime}}$.

[step 1] $(\Rightarrow)$ Now let us return to our main statement. For an arbitrarily given $n \in[\underline{n}, \bar{n}]$, suppose that the IC constraint and IR constraint are met. From Lemma 1, this implies that $V_{1}(n \mid n)=0$. Based on the Fundamental theorem of calculus, it follows that $V_{1}(n \mid n)=V(\underline{n} \mid \underline{n})+\int_{n}^{n} V_{1}(t \mid t)+$

$V_{2}(t \mid t) d t=V(\underline{n} \mid \underline{n})+\int_{\underline{n}}^{n}-\frac{l_{t}}{t} u_{2} d t \quad$ as $\quad V_{1}(t \mid t)=0 \quad$ and $V_{2}(t \mid t)=-\frac{l_{t}}{t} u_{2}$. This means that $v_{n}=v_{\underline{n}}+\int_{\underline{n}}^{n}-\frac{l_{t}}{t} u_{2} d t$ because $V(n \mid n)=E\left[u\left(w n l_{n}-T\left(r_{n} w n l_{n}\right)\right]=v_{n}\right.$ and $v_{\underline{n}}=$ $V(\underline{n} \mid \underline{n})=E\left[u\left(w L_{\underline{n}}-T\left(r_{\underline{n}} w L_{\underline{n}}\right)\right]\right.$.

Since $n>\underline{n}, v_{n} \geq v_{\underline{n}}$ based on [step 0]. Because $v_{n}=$ $v_{\underline{n}}+\int_{\underline{n}}^{n}-\frac{l_{t}}{t} u_{2} d t$, this means that $\int_{\underline{n}}^{n}-\frac{l_{t}}{t} u_{2} d t \geq 0$. Finally, this implies that $\int_{\underline{n}}^{\bar{n}}-\frac{l_{t}}{t} u_{2}\left[p \frac{1}{u_{1}^{D}}+(1-p) \frac{1}{u_{1}^{N D}}\right] d t \geq 0$ since both $u_{1}^{D}$ and $u_{1}^{N D}$ are always strictly positive and $p \in$ $(0,1)$.

[step 2] $(\Leftarrow)$ Conversely, suppose that (i) $v_{n}=v_{n}$ 
$+\int_{\underline{n}}^{n}-\frac{l_{t}}{t} u_{2} d t$, and that (ii) $\int_{\underline{n}}^{n}-\frac{l_{t}}{t} u_{2}\left[p \frac{1}{u_{1}^{D}}+(1-p) \frac{1}{u_{1}^{N D}}\right.$ ]$d t \geq 0$, for an arbitrarily given $n \in[\underline{n}, \bar{n}]$. By way of contradiction, assume that the IC constraint is not met. Then, there exists some $n^{\prime}<n$ such that $V(n \mid n)<V\left(n^{\prime} \mid n\right)$. This implies that $V\left(n^{\prime} \mid n\right)-V(n \mid n)=\int_{n}^{n^{\prime}} V_{1}(t \mid n) d t=-$ $\int_{n}^{n} V_{1}(t \mid n) d t>0$.

On the other hand, we can restate $v_{n}=v_{\underline{n}}+\int_{\underline{n}}^{n}-\frac{l_{t}}{t} u_{2} d t$ as $V(n \mid n)=V(\underline{n} \mid \underline{n})+\int_{\underline{n}}^{n} V_{2}(t \mid t) d t$ since $V(n \mid n)=v_{n}$ and $V_{2}(t \mid t)=-\frac{l_{t}}{t} u_{2}$. In turn, $V(n \mid n)=V(\underline{n} \mid \underline{n})+\int_{\underline{n}}^{n^{\prime}} V_{1}(t \mid t)+$ $V_{2}(t \mid t) d t$, based on the Fundamental theorem of calculus. This implies that $V_{1}(n \mid n)=0$. Furthermore, $\int_{\underline{n}}^{n} V_{1}^{\prime}(t \mid n) d t$ $=\int_{n}^{n^{\prime}} V_{1}(t \mid n)-V_{1}(t \mid t) d t \quad$ as $\quad V_{1}(n \mid n)=V_{1}(t \mid t)=0$. Since $V_{1}(t \mid n)=\left[p u_{1}^{D} w\left\{1-\left(1+\bar{\theta}-r_{t} \bar{\theta}\right) T^{\prime}\right\}+(1-p) u_{1}^{N D} w\left(1-r_{t} T^{\prime}\right)\right.$ ]$L^{\prime}+u_{2} \frac{1}{n} L^{\prime}$ and $V_{1}(t \mid t)=\left[p u_{1}^{D} w\left\{1-\left(1+\bar{\theta}-r_{t} \bar{\theta}\right) T^{\prime}\right\}+(1-\right.$ p) $\left.u_{1}^{N D} w\left(1-r_{t} T^{\prime}\right)\right] L^{\prime}+u_{2} \frac{1}{t} L^{\prime}, \quad V_{1}(t \mid n)-V_{1}(t \mid t)=u_{2} \frac{1}{n} L^{\prime}-$ $u_{2} \frac{1}{t} L^{\prime}=u_{2} L^{\prime}\left[\frac{1}{n}-\frac{1}{t}\right]$. Hence, $-\int_{n}^{n} V_{1}(t \mid n) d t=-\int_{n}^{n} u_{2} L^{\prime}\left[\frac{1}{n}-\right.$ $\left.\frac{1}{t}\right] d t<0$. This implies that $L^{\prime}=\frac{d L_{n}}{d n}>0$ because $u_{2}<0$ and $\frac{1}{n}-\frac{1}{t}<0$ for $\forall t \in\left(n^{\prime}, n\right)$. This is a contradiction to $-\int_{n}^{n} V_{1}(t \mid n) d t>0$. Therefore, the conditions (i) and (ii) in the above statement implies that the IC constraint is satisfied. Due to Lemma 2, this in turn implies that the IR constraint is also met if the above (i) and (ii) are met.

\section{Proof of Lemma 4.}

First of all, the left-hand side of (8) is greater than zero for $\forall n \in[n, \bar{n})$ and zero when $n=\bar{n}$. To see this, first, $\frac{d \pi_{n}}{d l_{n}}=\frac{d}{d l_{n}}\left(\frac{-l_{n}}{n} u_{2}\right)=\frac{-1}{n} u_{2}-\frac{l_{n}}{n} u_{22}>0 \quad$ since $\quad u \quad$ is decreasing in working hours $\left(u_{2}<0\right)$ and concave $\left(u_{22}<0\right)$. Second, $\left[\lambda\left\{p \frac{1}{u_{1}^{D}}+(1-p) \frac{1}{u_{1}^{N D}}\right\}-\frac{d^{2} G}{d v_{n}^{2}}\right] h(t)>0$ due to (i) $u_{1}^{D}>0$ and $u_{1}^{N D}>0$, (ii) $\frac{d^{2} G}{d v_{n}^{2}} \leq 0$ (weakly concave SWF) and (iii) $h(t)>0$ (full support). Thus, $\frac{d \pi_{n}}{d l_{n}}=\int_{n}^{\bar{n}}\left[\lambda\left\{p \frac{1}{u_{1}^{D}}+(1-p) \frac{1}{u_{1}^{N D}}\right\}-\frac{d^{2} G}{d v_{n}^{2}}\right] h(t)>0 \quad$ when $n<\bar{n}$. Moreover, it is equal to zero when $n=\bar{n}$ as $\int_{\bar{n}}^{\bar{n}}\left[\lambda\left\{p \frac{1}{u_{1}^{D}}+(1-p) \frac{1}{u_{1}^{N D}}\right\}-\frac{d^{2} G}{d v_{n}^{2}}\right] h(t)>0$. Second of all, in the right-hand side of (8), $w n \lambda\left[p\left\{1+\bar{\theta}\left(1-r_{n}\right)\right\}+(1-p) r_{n}\right]>0 \quad$ for $\quad \forall n \in[\underline{n}, \bar{n}] \quad$ as $r_{n} \in(0,1), \quad \bar{\theta}>0$ and $p \in(0,1) \quad$ for $\forall n \in[\underline{n}, \bar{n}]$. Therefore, for $n=\bar{n}, T^{\prime}=0$ following the sign of the left-hand side. By the similar token, as all of $w, n$, and $\lambda$ are greater than zero for $\forall n \in[\underline{n}, \bar{n}]$, $\left[p\left\{1+\bar{\theta}\left(1-r_{n}\right)\right\}+(1-p) r_{n}\right] T^{\prime}>0$ as the left-hand side is strictly positive.

\section{Proof of Theorem 1.}

[step 0] As a stepping stone to prove Theorem 1, we first need to show that $T^{\prime}>0$ for $\forall n \in[\underline{n}, \bar{n})$. First, $p\{1+\bar{\theta}(1$ $\left.\left.-r_{n}\right)\right\}+(1-p) r_{n}>0 \quad$ since $r_{n} \in(0,1), \quad \bar{\theta}>0 \quad$, and $p \in(0,1)$ for $\forall n \in[\underline{n}, \bar{n}]$. From Lemma 4, this means that $T^{\prime}>0$ for any $n \in[\underline{n}, \bar{n})$.

[step 1] Based on the Implicit Function Theorem, using (8), we can obtain $\frac{d r_{n}}{d T^{\prime}}=\frac{-w n \lambda\left[p\left\{1+\bar{\theta}\left(1-r_{n}\right)\right\}+(1-p) r_{n}\right] h(n)}{w n \lambda[-p \bar{\theta}+(1-p)] T^{\prime} h(n)}=$ $\frac{-\left[p\left\{1+\bar{\theta}\left(1-r_{n}\right)\right\}+(1-p) r_{n}\right]}{[-p \bar{\theta}+(1-p)] T^{\prime}}$ for $\forall n \in[\underline{n}, \bar{n}]$. As shown in the [step 0], $\left[p\left\{1+\bar{\theta}\left(1-r_{n}\right)\right\}+(1-p) r_{n}\right]>0$. In addition to this, from [step 0] and the interior solution condition of $\frac{p \theta}{(1-p)}<1, \quad[-p \bar{\theta}+(1-p)] T^{\prime}>0$. Moreover, because $T^{\prime}=0 \quad$ at $\quad n=\bar{n} \quad($ Lemma $\quad 4), \quad \frac{d r_{n}}{d T^{\prime}}=-\infty \quad$ at $n=\bar{n}$. Therefore, $\frac{d r_{n}}{d T^{\prime}}<0$ for $\forall n \in[\underline{n}, \bar{n}]$. Since $e_{n}=1-r_{n}$, $\frac{d e_{n}}{d r_{n}}<0$. Taken together, this finally implies that $\frac{d e_{n}}{d T^{\prime}}>0$ for $\forall n \in[\underline{n}, \bar{n}]$ since $\frac{d e_{n}}{d T^{\prime}}=\frac{d e_{n}}{d r_{n}} \frac{d r_{n}}{d T^{\prime}}$.

\section{Proof of Theorem 2.}

[step 0] First, we need to show that $T^{\prime}>0$ for $\forall n \in[\underline{n}, \bar{n})$. Because $r_{n} \in(0,1), \bar{\theta}>0$, and $p \in(0,1)$ result in $\left[p\left\{1+\bar{\theta}\left(1-r_{n}\right)\right\}+(1-p) r_{n}\right]>0$, which implies that $T^{\prime}>0$ for any $n \in[\underline{n}, \bar{n})$ from Lemma 4.

[step 1] Based on the Implicit Function Theorem, using (3), we can obtain, for $\forall n \in[\underline{n}, \bar{n}]$, 


$$
\frac{d r_{n}}{d p}=\frac{-\left(\bar{\theta} u_{1}^{D}+u_{1}^{N D}\right)}{\left[p \bar{\theta}^{2} u_{11}^{D}+(1-p) u_{11}^{N D}\right] w n l_{n} T^{\prime}} .
$$

Firstly, $\bar{\theta} u_{1}^{D}+u_{1}^{N D}$ because $u$ increases in consumption and $\bar{\theta}>0$. Secondly, because $\bar{\theta}^{2}>0, p \in(0,1)$, $w n l_{n}>0, T^{\prime}>0$ for $\forall n \in[\underline{n}, \bar{n})$ due to the [step0], and $u$ is concave in consumption ( $\left.u_{11}<0\right)$, $\left[p \bar{\theta}^{2} u_{11}^{D}+(1-p) u_{11}^{N D}\right] w n l_{n} T^{\prime}<0$ for $\forall n \in[\underline{n}, \bar{n})$ whereas $\left[p \bar{\theta}^{2} u_{11}^{D}+(1-p) u_{11}^{N D}\right] w n l_{n} T^{\prime}=0$ for $n=\bar{n}$ because $T^{\prime}=0$ at $n=\bar{n}$ (Lemma 4). This implies that $\frac{d r_{n}}{d p}>0$ for $\forall n \in[\underline{n}, \bar{n})$ while $\frac{d r_{n}}{d p}=\infty \quad$ at $n=\bar{n}$. Therefore, $\frac{d r_{n}}{d p}>0$ for $\forall n \in[\underline{n}, \bar{n}]$. As $e_{n}=1-r_{n}$, this implies that $\frac{d e_{n}}{d p}=\frac{d e_{n}}{d r_{n}} \frac{d r_{n}}{d p}<0$ for $\forall n \in[\underline{n}, \bar{n}]$.

\section{REFERENCES}

[1] Slemrod, Joel. Cheating Ourselves: the Economics of Tax Evasion, Journal of Economic Perspectives. 21, 25-48, 2007.

[2] IMF Fiscal Affairs Department. Revenue Mobilization in Developing Countries, International Monetary Fund Policy Paper, 2011.

[3] Allingham, Michael, and Agnar Sandmo. Income Tax Evasion: A Theoretical analysis, Journal of Public Economics, Vol.1, No.3, 323-338, 1972.

[4] Pencavel, John H. A Note on Income Tax Evasion, Labor Supply, and Nonlinear Tax Schedules, Journal of Public Economics, 12, 115-124, 1979.

[5] Baldry, Jonathan C. Tax Evasion and Labour Supply, Economics Letters, Vo. 3, No.1, 53-56, 1979.

[6] Horowitz, Ira, and Ann R. Horowitz. Tax Audit Uncertainty and the Work-versus-leisure Decision, Public Finance Review, 28, 491-510, 2000.

[7] Sandmo, Agnar. Income Tax Evasion, Labour Supply, and the Equity-efficiency Tradeoff, Journal of Public Economics, 16, 265-288, 1981

[8] Chander, P., and L. L. Wilde. A General Characterization of Optimal Income Tax Enforcement, Review of Economic Studies, 65,165-183, 1998.

[9] Mirrlees, James A. An Exploration in the Theory of Optimum Income Taxation, Review of Economic Studies, 38, 175-208, 1971.

[10] Jacquet, Laurence, Etienne Lehmann, and Bruno Van Der Linden. Optimal Redistributive Taxation with Both Extensive and Intensive Responses, Journal of Economic Theory, 148, 1770-1805, 2013.

[11] Reinganum, Jennifer F, and Louis L. Wilde. Income Tax Compliance in A Principal-agent Framework, Journal of Public Economics, 26, 1-18, 1985.

[12] Mookherjee, Dilip, and Ivan Png. Optimal Auditing, Insurance, and Redistribution, Quarterly Journal of Economics, 104, 399-415, 1989.

[13] Sánchez, Isabel, and Joel Sobel. Hierarchical Design and Enforcement of Income Tax Policies, Journal of Public Economics, 50, 345-369, 1993.

[14] Guyton J, O'hare J, Stavrianos M, and Toder E. Estimating the Compliance Cost of the U.S. Individual Income Tax, National Tax Journal, 56, 673-688, 2003.

[15] Clotfelter Charles T. Tax Evasion and Tax Rates: An Analysis of Individual Returns, Review of Economics and Statistics, 65, 363-373, 1983.

[16] Baldry, Jonathan C. Income Tax Evasion and the Tax Schedule: Some Experimental Results, Public Finance, Vol.42, 357-383, 1987.

[17] Dubin, J.A, M.J. Graetz, and L.L. Wilde. The Effect of Audit Rates on the Federal Individual Income Tax, 1977-1986, National Tax Journal, 43, 395-409, 1990.

[18] Alm, James, Betty R. Jackson, and Michael McKee. Estimating the Determinants of Taxpayer Compliance with Experimental Data, National Tax Journal, Vol.45, No.1, 107-114, 1992. 